\title{
Stendhal, Romanzi e Racconti
}

\section{Annalisa Bottacin}

\section{Q OpenEdition}

\section{Journals}

\section{Edizione digitale}

URL: https://journals.openedition.org/studifrancesi/39556

DOI: 10.4000/studifrancesi.39556

ISSN: 2421-5856

\section{Editore}

Rosenberg \& Sellier

\section{Edizione cartacea}

Data di pubblicazione: 1 décembre 2004

Paginazione: 386-387

ISSN: 0039-2944

\section{Notizia bibliografica digitale}

Annalisa Bottacin, «Stendhal, Romanzi e Racconti», Studi Francesi [Online], 143 (XLVIII | II) | 2004, online dal 30 novembre 2015, consultato il 19 mai 2021. URL: http://journals.openedition.org/studifrancesi/ 39556 ; DOI: https://doi.org/10.4000/studifrancesi.39556

Questo documento è stato generato automaticamente il 19 mai 2021.

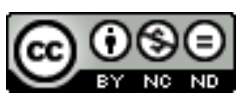

Studi Francesi è distribuita con Licenza Creative Commons Attribuzione - Non commerciale - Non opere derivate 4.0 Internazionale. 


\title{
Stendhal, Romanzi e Racconti
}

\author{
Annalisa Bottacin
}

\section{NOTIZIA}

STENDHAL, Romanzi e Racconti. Volume secondo. Introduzione e note ai testi di M. DI MAIO, Cronologia di M. CROUZET. Traduzioni di M. CUCCHI, Milano, Mondadori, 2001 ("I

Meridiani"), pp. 1431.

1 Il secondo volume della dotta e raffinata edizione dell'opus stendhaliano a cura di Mariella Di Maio, con traduzioni di Maurizio Cucchi (che proprio per questo lavoro ha ottenuto un importante riconoscimento), ripropone ad apertura del testo, la cronologia stendhaliana redatta da Michel Crouzet (pp. XI-XLIII) che appariva già nel tomo precedente, supporto essenziale e strumento utilissimo per il lettore nella ricognizione dei lavori di Henri Beyle, così strettamente legati al biografismo. Il volume debutta con Lucien Leuwen, di cui la curatrice, nell'accuratissima e corposa introduzione (pp. 17-63) ne traccia la problematica stesura, narrandone la gestazione e rivelando altresì al lettore l'importanza del romanzo, forse troppo trascurato, nella narrativa stendhaliana. Di Maio puntualizza come nel tracciato diegetico sia presente una particolare incertezza da parte dell'autore, per altro afferma che «l'indecisione sul titolo e sulla fine del romanzo accompagnano abbastanza regolarmente una gestazione lunga e tormentata». (p. 17). Le pagine dedicate a Lucien Leuwen non comportano unicamente una mera traduzione del romanzo, ma vengono inserite le prefazioni e parti essenziali relative ad esso, che, per la prima volta si trovano accostate. In primo luogo la curatrice propone una dettagliata ricostruzione della sua genesi; dalla corrispondenza di Stendhal con Madame Jules Gaulthier per il suo Lieutenant, da cui il grenoblese si ispirò per Lucien Leuwen, alle varie fasi di scrittura e ai vari titoli prescelti, fino alla lignée di esso, rappresentata forse da Une position sociale (pp. 1205-37). Basandosi sul manoscritto autografo, conservato presso la Bibliothèque Municipale di Grenoble, Di Maio evidenzia la complessità del processo creativo stendhaliano, relativamente a Lucien Leuwen, rimasto come molti altri un «texte inachevé» (v. Il cacciatore verde Lucien Leuwen, pp. 69-804), che si appoggia su un eccellente saggio della stessa, denso di 
note e notizie assai interessanti e sovente sconosciute ai non addetti ai lavori. Accanto a Lucien Leuwen, si leggono nei Racconti e abbozzi narrativi, sempre corredati da introduzione e note della curatrice (pp. 805-1202), Ricordi di un gentiluomo italiano (pp. 833-64), Il cofano e il fantasma (pp. 865-88), Il filtro (pp. 889-906), Philibert Lescale (pp. 907-10), Mina de Vanghel (pp. 911-50), L'ebreo (pp. 951-68), Una posizione sociale (pp. 969-1010), Il Rosa e il Verde (pp. 1011-1092), Il cavaliere de Saint-Ismier (pp. 1093-1112), Féder (pp. 1113-1202). Nell'Appendice critica, appare nella traduzione della stessa Di Maio, il saggio che Paul Valéry scrisse come Prefazione all'edizione Champion (1926-27) di Lucien Leuwen, a cura di H. Debraye (pp. 1297-1308), seguito da un approfondito contributo della studiosa (Sullo "Stendhal" di Paul Valéry, pp. 1297-1307) in cui - come nota Di Maio - «presentiamo qualche riflessione critica che ci sembra del tutto doverosa in presenza di un testo così arduo e provocatorio» (p. 1261). Una bibliografia esaustiva e aggiornata (pp. 1417-25) completa quest'importante contributo per altro assai innovativo nella sua modernità, che apre la via a nuove conclusioni critiche in una particolare produzione scritturale, fino ad oggi non esaurientemente studiata. 